\title{
Frequency of arylsulphatase A pseudodeficiency associated mutations in a healthy population
}

\author{
Maria Luiza Barth, Chandra Ward, Ann Harris, Adnan Saad, Anthony Fensom
}

\begin{abstract}
Arylsulphatase A (ASA, EC 3.1.6.1) is a lysosomal enzyme that catalyses cerebroside sulphate degradation. ASA deficiency is associated with metachromatic leucodystrophy (MLD), a rare autosomal recessive disorder, which is characterised by the storage of cerebroside sulphate. Low ASA activities can be also observed in clinically healthy persons, a condition termed ASA pseudodeficiency. Two mutations responsible for the majority of pseudodeficiency alleles have been defined in the ASA gene. These are both $A \rightarrow G$ transitions. One causes an asparagine to serine substitution (N350S). The second changes the first polyadenylation signal downstream of the stop codon $(1524+95 \mathrm{~A} \rightarrow \mathrm{G})$, which causes a severe deficiency of one ASA mRNA species. The incidence of the pseudodeficiency allele is estimated to be high in the general population and can be found in families carrying MLD associated mutations. We report a reliable stratagem for detecting the two PD associated mutations separately, which we have applied to a healthy population. Two homozygotes for the N350S and $1524+95 A \rightarrow G$ mutations were detected, which gives a population frequency of $2 \cdot 6 \%$. The overall frequencies of the ASA-PD mutations were shown to be $17.5 \%$ for the N350S change and $13 \cdot 0 \%$ for the $1524+95 \mathrm{~A} \rightarrow \mathrm{G}$ change, estimating each mutation separately. In addition, the frequency of both PD associated mutations occurring together on the same chromosome was found to be $12 \cdot 3 \%$ in our population. The study has also allowed us to establish a new control ASA activity range, which was based on assay of blood from persons who had been shown at the DNA level not to carry ASA PD associated mutations.
\end{abstract}

\section{( $($ Med Genet 1994;31:667-671)}

Arylsulphatase A (ASA, EC 3.1.6.1) is a lysosomal enzyme that catalyses cerebroside sulphate degradation. ASA deficiency is associated with metachromatic leucodystrophy (MLD), a rare autosomal recessive disorder, which is characterised by the storage of cerebroside sulphate. ${ }^{1}$ The accumulation of this substrate can be found in many tissues of MLD patients, but affects mainly the nervous system. MLD can be divided into three major clinical forms: late infantile, juvenile, and adult, and the disease incidence is estimated to be around 1:40 000. ${ }^{2}$ The ASA gene maps to the long arm of chromosome 22 and spans $3.2 \mathrm{~kb}$ of genomic DNA divided into eight exons. ${ }^{3}$ The ASA cDNA hybridises to three different mRNA species and would be predicted to code for a protein of 507 amino acids that contains three potential $\mathrm{N}$-glycosylation sites. ${ }^{3+}$ Two mutations in the ASA gene are responsible for about $50 \%$ of the MLD associated mutations in the populations studied to date in northern Europe. ${ }^{56}$ One is a $\mathrm{G} \rightarrow \mathrm{A}$ change destroying the splice donor site of intron $2(459+1 \mathrm{G} \rightarrow \mathrm{A})$ and the other is a $\mathrm{C} \rightarrow \mathrm{T}$ transition causing a proline to leucine substitution (P426L) in exon 8 .

A much more frequent condition, termed ASA pseudodeficiency (PD), is also characterised by low ASA activities. This phenomenon can be seen in clinically healthy persons and its population incidence is estimated to be between $7 \cdot 3$ and $15 \% .^{7-9}$ Two mutations responsible for the majority of pseudodeficiency alleles have been defined in the ASA gene. These are both $A \rightarrow G$ transitions at base 1049 and base 1620 (numbering according to cDNA sequence ${ }^{4}$. One causes an asparagine to serine substitution (N350S), which leads to the loss of an $\mathrm{N}$-glycosylation site. The second changes the first polyadenylation signal downstream of the stop codon $(1524+95 \mathrm{~A} \rightarrow \mathrm{G})$, which causes a severe deficiency of one ASA mRNA species. The loss of this ASA mRNA species accounts for the reduced synthesis of ASA protein and the resultant lower enzyme activity in PD persons. ${ }^{10}$

Owing to the high frequency of the ASA PD allele in the general population, it is not surprising that this allele is also found to be segregating in some families carrying MLD associated mutations. This leads to additional difficulty in the establishment of diagnosis of MLD, particularly in prenatal diagnosis. This diagnostic problem necessitated the development of simple and straightforward methods for the detection of the two PD associated mutations in the ASA gene. A PCR based method was recently developed to enable the detection of ASA-PD alleles. ${ }^{11}$ This method relies on using allele specific oligonucleotides 


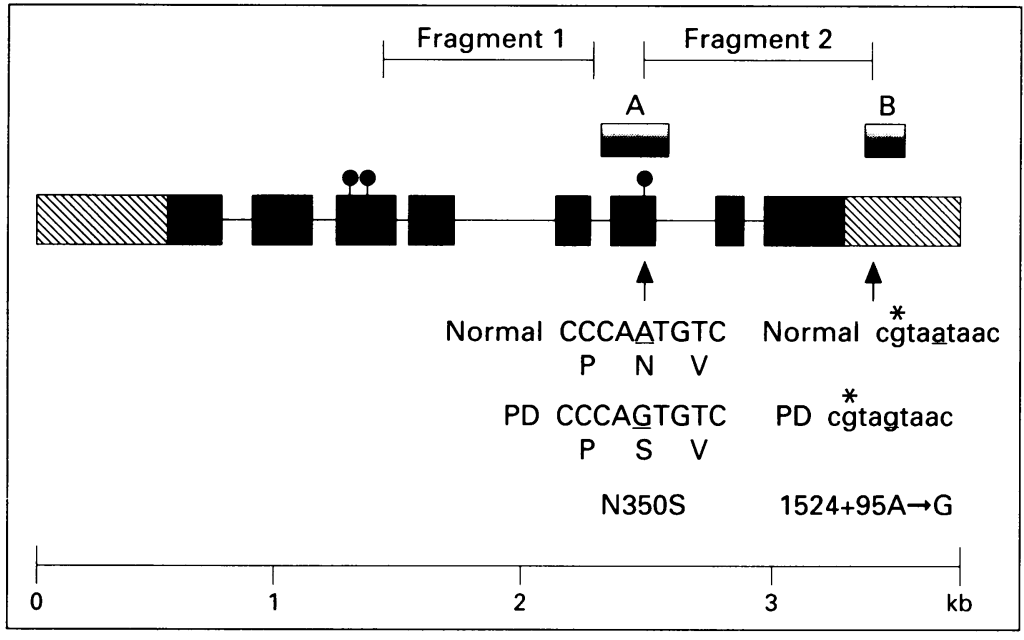

Figure 1 Mutations associated with ASA pseudodeficiency. Solid boxes indicate exons and hatched parts untranslated regions. Circles denote potential sites of $N$-glycosylation. Shaded boxes indicate fragments $A$ and $B$, which represent genomic DNA amplified for detection of mutations associated with ASA pseudodeficiency. Asterisk represents the site of an introduced mismatch $(t)$ for creation of a DdeI restriction site.

to amplify PCR products from either normal or PD alleles. However, although this assay is useful for identifying persons who carry both PD associated mutations on the same chromosome, it will not detect PD alleles that carry only one of these mutations. PD alleles carrying only one of these mutations have recently been described. ${ }^{12}$ We present here a reliable stratagem for detecting the two PD associated mutations separately. The approach combines PCR and restriction endonuclease digestion. We have examined a healthy population by this new method and established the frequency of the two mutations in this population.

\section{Materials and methods}

Throughout this manuscript we refer to nucleotide sequence of the ASA cDNA, except when otherwise stated.

\section{DNA PREPARATION}

Genomic DNA was extracted from mouthwash samples ${ }^{13}$ from 77 healthy persons.

POLYMERASE CHAIN REACTION AMPLIFICATION Two fragments of the ASA gene (fig 1) were amplified by PCR using the following oligonucleotide primers designed from the ASA genomic sequence (EMBL X52150).

Fragment A:

ASA $6 \mathrm{i}-5^{\prime}\left(5^{\prime}-3^{\prime}\right)$

TTGATGGCGAACTGAGTGAC

ASAp 6i-3' (5'-3')

CAGTGCAGGAGGCACTGAGG

$275 \mathrm{bp}$

Fragment B:

$\left.\begin{array}{l}\text { ASA E-5' }\left(5^{\prime}-3^{\prime}\right) \\ \text { GGTTTGTGCCTGATAAC*TA } \\ \begin{array}{l}\text { ASAp 8i-3' }\left(5^{\prime}-3^{\prime}\right) \\ \text { TTCCTCATTCGTACCACAGG }\end{array}\end{array}\right\} 114 \mathrm{bp}$.

(*indicates a mismatch site at position $1524+92)$
For the reaction, $500 \mathrm{ng}$ of each pair of exon specific primers was added to approximately 200 ng of template DNA with 2.5 units of Taq polymerase (Promega). Genomic DNA was amplified in a total volume of $25 \mu \mathrm{l}$ containing $0.2 \mathrm{mmol} / 1 \mathrm{dNTPs}, 9 \%$ dimethylsulphoxide, $10 \mathrm{mmol} / \mathrm{l}$ Tris- $\mathrm{HCl} \mathrm{pH} 9,50 \mathrm{mmol} / 1 \mathrm{KCl}$, $1.5 \mathrm{mmol} / 1 \mathrm{MgCl}_{2}, 170 \mu \mathrm{g} \mathrm{ml}{ }^{1}$ bovine serum albumin, and $0 \cdot 1 \%$ Triton $\mathrm{X}-100$. The reaction parameters were $94^{\circ} \mathrm{C}$ for five minutes, then 30 cycles of $94^{\circ} \mathrm{C}$ for 30 seconds, followed by 30 seconds at $60^{\circ} \mathrm{C}$ (fragment $\mathrm{A}$ ) or $58^{\circ} \mathrm{C}$ (fragment $\mathrm{B}$ ), then $72^{\circ} \mathrm{C}$ for 30 seconds followed by five minutes' extension at $72^{\circ} \mathrm{C}$. One fifth of the PCR reaction was analysed on a $2 \%(\mathrm{w} / \mathrm{v})$ agarose gel.

\section{DETECTION OF THE N350s MUTATION}

The N350S mutation creates a BsrI site, so population screening for this mutation was carried out by $B s r \mathrm{I}$ restriction digest of amplified fragment A (fig 1). Approximately $400 \mathrm{ng}$ of PCR product was digested in $40 \mu 1$ reaction, using $10 \mathrm{U}$ of $B s r \mathrm{I}$ in $150 \mathrm{mmol} / 1 \mathrm{KCl}$, $10 \mathrm{mmol} / 1$ Tris- $\mathrm{HCl}, 10 \mathrm{mmol} / 1 \mathrm{MgCl}_{2}$, and $20 \mu \mathrm{g}$ bovine serum albumin. The reaction products were then analysed by electrophoresis on a $2.5 \%(\mathrm{w} / \mathrm{v})$ agarose gel. In the presence of the mutation the $275 \mathrm{bp}$ fragment $A$ is cleaved into two smaller fragments of $161 \mathrm{bp}$ and $114 \mathrm{bp}$.

DETECTION OF $1524+95 \mathrm{~A} \rightarrow \mathrm{G}$

In this case, a mismatched primer (ASA E-5') was used in the PCR reaction. In the presence of the $1524+95 \mathrm{~A} \rightarrow \mathrm{G}$ mutation, a DdeI site is generated. Hence, DdeI cleavage of fragment $\mathrm{B}$ was used to screen for this mutation. Approximately $400 \mathrm{ng}$ of PCR product was digested in $40 \mu \mathrm{l}$ reaction, using $10 \mathrm{U}$ of $\mathrm{DdeI}$ in $10 \mathrm{mmol} / \mathrm{l}$ spermidine, $100 \mathrm{mmol} / 1 \mathrm{NaCl}$, $50 \mathrm{mmol} / 1$ Tris- $\mathrm{HCl}, 10 \mathrm{mmol} / 1 \mathrm{MgCl}_{2}$, and $1 \mathrm{mmol} / 1$ dithiothreitol. The reaction products were analysed by electrophoresis on a $10 \%$ $(\mathrm{w} / \mathrm{v})$ polyacrylamide gel. In the presence of the mutation the full PCR product of $114 \mathrm{bp}$ is cleaved into two smaller fragments of $97 \mathrm{bp}$ and $17 \mathrm{bp}$. The $17 \mathrm{bp}$ fragment is too small to be resolved on the gels used and so mutation detection depends solely on the generation of a $97 \mathrm{bp}$ fragment.

DNA AMPLIFICATION FOR DETECTION OF THE N350S AND $1524+95 \mathrm{~A} \rightarrow \mathrm{G}$ MUTATIONS ON THE SAME CHROMOSOME

Fragments 1 and 2 (fig 1) were amplified according to a method described previously by Gieselmann. ${ }^{11}$ This method uses two pairs of primers for amplification of the region between the two mutations (fragment 2). One pair of primers is homologous to the normal ASA sequence and allows amplification of fragment 2 when neither mutation is present. The other pair of primers is homologous to the mutant sequence and a product is generated only when both mutations are present on the same chromosome. Fragment 1, an internal positive con- 
A

$1.23 \quad 4$

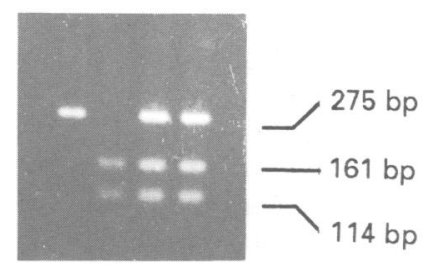

B

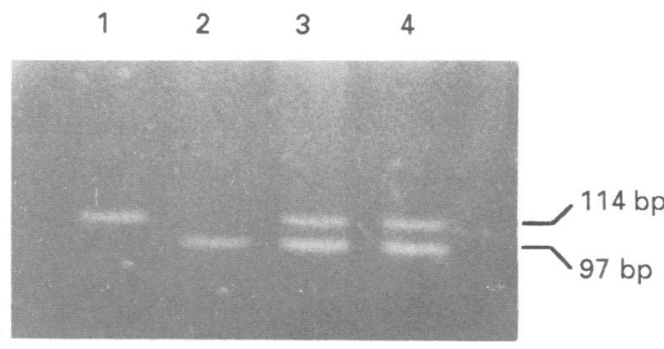

Figure 2 Detection of $N 350 S$ and $1524+95 A \rightarrow G$ mutations. (A) Detection of N350S mutation: fragment $A$ was amplified by PCR, products were digested with BsrI and fractionated in a $2.5 \%$ (w/v) agarose gel. Lane 1 is homozygous for normal sequence; lane 2 is homozygous for mutant sequence; lanes 3 and 4 are heterozygotes. (B) Detection of $1524+95 A \rightarrow G$ mutation: fragment $B$ was amplified by $P C R$, products were digested with DdeI and fractionated in a $10 \%$ polyacrylamide gel. Lane 1 is homozygous for normal sequence; lane 2 is homozygous for mutant sequence; lanes 3 and 4 are heterozygotes.

trol for the assay, is amplified from all ASA genes. Primer sequences for this assay are as described previously. ${ }^{11}$

\section{ASA ENZYME ASSAY IN LEUCOCYTES}

Leucocytes (WBC) were isolated from a $10 \mathrm{ml}$ heparinised blood sample by the dextran sedimentation method ${ }^{14}$ and stored at $-30^{\circ} \mathrm{C}$. Each WBC pellet was resuspended in $500 \mu \mathrm{l}$ of deionised water and disrupted by sonication. Total protein concentration was determined by the method of Lowry et al. ${ }^{15}$ ASA activity was determined in sonicated WBC pellets using 4-nitrocatechol sulphate as the substrate, as described by Lee-Vaupel and Conzelmann, ${ }^{16}$ with an incubation time of 18 hours at $0^{\circ} \mathrm{C}$ and protein content of 100-150 $\mu \mathrm{g} /$ assay.

DIRECT SEQUENCE ANALYSIS OF PCR PRODUCTS PCR amplified DNA was purified using Geneclean II (Bio101) and sequenced by standard methods with Sequenase (USB) and appropriate primers. ${ }^{17}$

\section{Results}

VERIFICATION OF THE N350S ASSAY

Fig 2A shows the results obtained for the detection of the N350S mutation. The presence of the $275 \mathrm{bp}$ full length fragment A alone indicates a subject who is homozygous for the normal sequence (fig $2 \mathrm{~A}$, lane 1 ). In persons who are homozygous for the N350S mutation, the amplified fragment $A$ is cleaved and two smaller fragments of $161 \mathrm{bp}$ and $114 \mathrm{bp}$ are seen (fig 2A, lane 2). Persons who are heterozygous for the N350S mutation show three fragments after $B s r I$ digestion of fragment A, the $275 \mathrm{bp}$ product from the normal allele, and the $161 \mathrm{bp}$ and $114 \mathrm{bp}$ fragments from the allele carrying the N350S mutation (fig $2 \mathrm{~A}$, lanes 3 and 4 ). In each case, the mutation was confirmed by direct sequence analysis.

VERIFICATION OF THE $1524+95 \mathrm{~A} \rightarrow \mathrm{G}$ ASSAY Results from the assay for the detection of the $1524+95 \mathrm{~A} \rightarrow \mathrm{G}$ mutation are shown in fig $2 \mathrm{~B}$. The $5^{\prime}$ primer used in the amplification of fragment B contains a mismatched base (relative to the normal genomic DNA sequence)
Summary of genotypes found

\begin{tabular}{lll}
\hline Genotypes & & $\begin{array}{l}\text { No of } \\
\text { subjects }\end{array}$ \\
\hline N350S & $1524+95 A \rightarrow G$ & 2 \\
$+/+$ & $+1+$ & 1 \\
$+/+$ & $-1-$ & 16 \\
$+/-$ & $+/-$ & 5 \\
$+/-$ & $-/-$ & 53 \\
$-/-$ & $-/-$ & \\
\hline
\end{tabular}

$-/$ - represents homozygous for normal sequence. +1 - represents heterozygous.

$+1+$ represents homozygous for mutant sequence.

that generates a restriction site for $D d e \mathrm{I}$ in the presence of the $1524+95 \mathrm{~A} \rightarrow \mathrm{G}$ mutation. After $D d e I$ digestion of fragment $\mathrm{B}$, a subject who is homozygous for the normal sequence shows a single full length fragment $B$ of $114 \mathrm{bp}$ (fig $2 \mathrm{~B}$, lane 1). A person who is homozygous for $1524+95 \mathrm{~A} \rightarrow \mathrm{G}$ shows a single smaller fragment of $97 \mathrm{bp}$ (fig 2B, lane 2) (the $17 \mathrm{bp}$ product is not resolved on the gels used here). In a subject who is heterozygous for the $1524+95 \mathrm{~A} \rightarrow \mathrm{G}$ mutation, two fragments of $114 \mathrm{bp}$ and $97 \mathrm{bp}$ are observed (fig $2 \mathrm{~B}$, lanes 3 and 4). Results were confirmed by sequence analysis.

POPULATION FREQUENCIES OF THE N350S AND $1524+95 \mathrm{~A} \rightarrow \mathrm{G}$ MUTATIONS

A summary of $\mathrm{N} 350 \mathrm{~S}$ and $1524+95 \mathrm{~A} \rightarrow \mathrm{G}$ mutation genotypes found in our population is shown in the table. We have detected mutations in 24 out of 77 persons screened. Two were homozygous for both mutations, 16 were heterozygous for both of them, and five were heterozygous for the N350S mutation alone. One was homozygous for the N350S mutation alone.

The 16 persons who were shown to be heterozygous for both mutations were re-screened using the method described by Gieselmann ${ }^{11}$ in order to establish whether both mutations were located on the same chromosome. The results obtained using this method showed that 15 of these 16 persons carried the N350S and $1524+95 \mathrm{~A} \rightarrow \mathrm{G}$ mutations on the same chromosome. However, one showed no amplification of the mutant or normal fragments, despite amplification of the internal control fragment, suggesting that the two mutations were located on different chromosomes. 


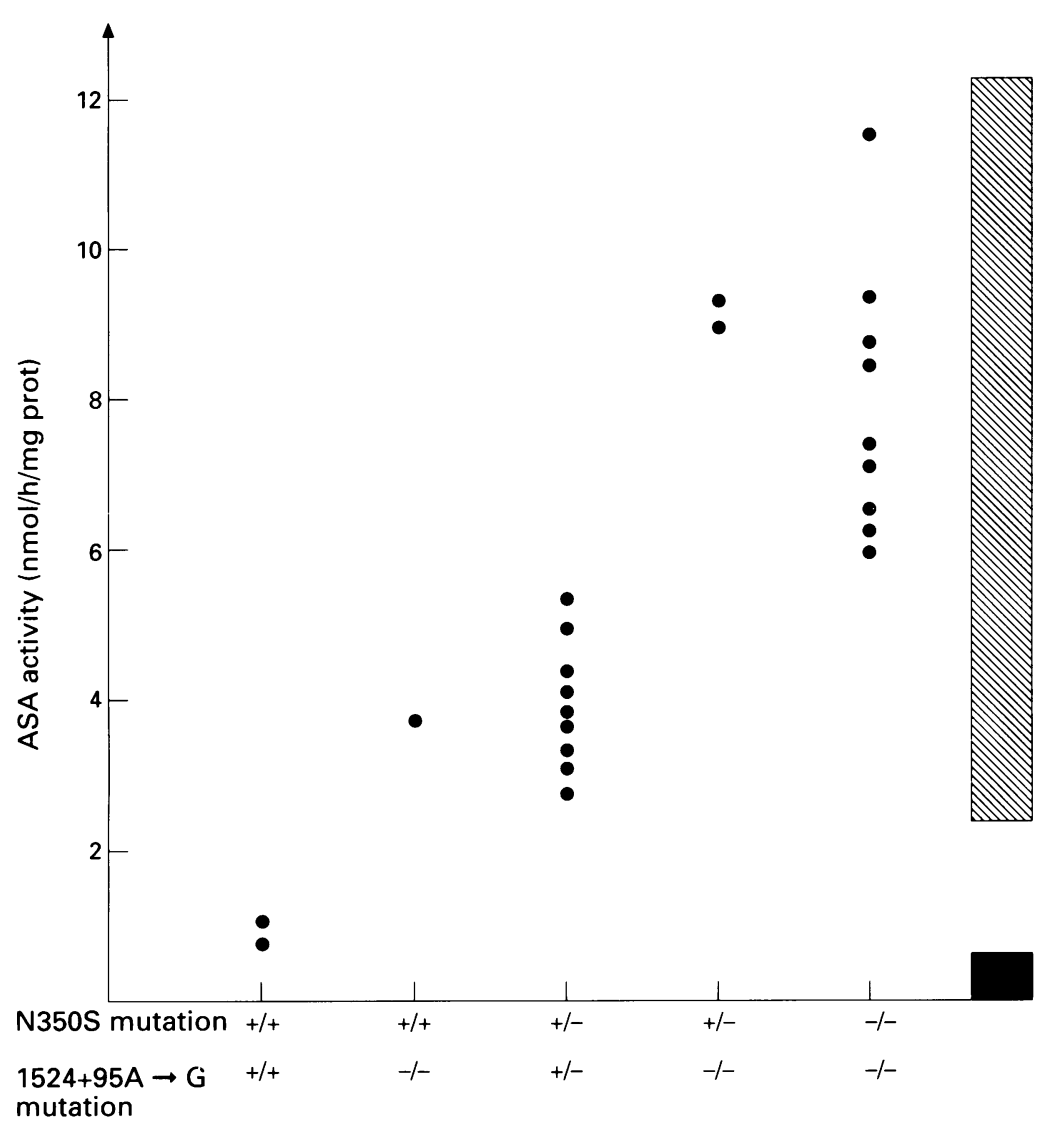

Genotypes

Figure 3 Relationship between ASA activity and genotype. - / - represents homozygous for normal sequence; $+1-$ represents heterozygous; $+1+$ represents homozygous for mutant sequence; solid bar denotes MLD range; hatched bar indicates previous control range. that these two mutations do not always occur together and that at least the N350S mutation may be found alone. ${ }^{912}$ To date the $1524+95 \mathrm{~A} \rightarrow \mathrm{G}$ mutation has not been reported in isolation.

We have developed a new approach to detect the ASA PD associated mutations separately instead of using the combined PCR based method described by Gieselmann. ${ }^{11}$ This approach allowed us to establish the frequency of the different genotypic groups within our normal population. Subjects from each group were reassessed in order to establish the relationship between ASA PD genotype and ASA enzyme activity.

We have detected two homozygotes for the $\mathrm{N} 350 \mathrm{~S}$ and $1524+95 \mathrm{~A} \rightarrow \mathrm{G}$ mutations, which gives a population frequency of $2 \cdot 6 \%$ (four of 154 alleles). The ASA enzyme activities of these two persons were found to be just above the MLD range (fig 3), with values of 0.7 and $1.0 \mathrm{nmol} / \mathrm{h} / \mathrm{mg}$ protein, while the control range was established to be from 6.0 to $11.6 \mathrm{nmol} / \mathrm{h} /$ $\mathrm{mg}$ protein. Sixteen persons were found, by our method of detection, to be heterozygous for both mutations. When these 16 persons were then rescreened by the method described by Gieselmann, ${ }^{11}$ which gives positive results only when both mutations are located on the same chromosome, 15 subjects appeared to carry the ASA PD allele. Hence, one person presumably carries the two mutations on different chromosomes. ASA activities were also measured in eight persons who are heterozygous for both mutations and carry them on the same chromosome (fig 3) and from the person who presumably carries the two mutations on different chromosomes. All these persons were found to have lower ASA activities than those who are homozygotes for the normal sequence. However, their activities fall within the ASA activity range established previously for normal ASA alleles, at the lower end of the range. This result suggests that the normal ASA activity range established previously on a control group drawn from the same population probably included samples from persons carrying the $\mathrm{PD}$ allele.

The one subject who was found to be homozygous for the N350S mutation had an ASA activity (fig 3 ) of $3.9 \mathrm{nmol} / \mathrm{h} / \mathrm{mg}$ protein, while the control range was determined to be 6.0 to $11.6 \mathrm{nmol} / \mathrm{h} / \mathrm{mg}$ protein. This shows that the homozygote for the N350S mutation in this study has an ASA activity below the normal range, but similar to those of heterozygotes for both mutations. Five persons were found to be heterozygotes for the N350S mutation alone and the two of these who were available for measurement of ASA activity had levels within the normal range. These results indicate that the N350S mutation alone does not seem to be responsible for a major reduction of ASA activity in our population. Although the numbers studied by us are still small, the observations confirm the data of Gieselmann et $a l .{ }^{10}$

The overall frequencies of the ASA PD mutations have been shown here to be $17 \cdot 5 \%(27$ of 154 alleles) for the N350S change and $13.0 \%$ pseudodeficiency was first defined as an allele carrying two linked lesions in the ASA gene, the N350S and the $1524+95 \mathrm{~A} \rightarrow \mathrm{G}$ mutations. ${ }^{10}$ However, recent data have shown 
(20 of 154 alleles) for the $1524+95 \mathrm{~A} \rightarrow \mathrm{G}$ change. These frequencies have been estimated for each mutation separately. In addition, the frequency of both PD associated mutations occurring together on the same chromosome was estimated to be $12.3 \%$ ( 19 of 154 alleles) in our population. The frequency of the PD allele obtained here is higher than the data obtained in the Australian $(9 \cdot 6 \%)^{9}$ and German $(7 \cdot 3 \%)^{8}$ populations. This variation may be because of different assays used in each study. The method used here enables the establishment of the frequency of the ASA PD associated mutations alone as well as the frequency of the ASA PD allele carrying both mutations. The study has also allowed us to establish a new control ASA activity range, which was calculated using measurements on persons who had been shown at the DNA level not to carry ASA PD associated mutations. The data obtained in this study will be useful in precise diagnosis of mutation status in families segregating PD associated as well as MLD associated mutations.

The authors are grateful to all volunteers who kindly provided The authors are grateful to all volunteers who kindly provided the samples used in this study. The authors would also like to thank Dr S Abbs for his help with this work and Drs $E$ MLB was supported by CNPq, Brazil. The work was also MLB was supported by CNPq, Brazil. The work was also supported

1 Kolodny EH. Metachromatic leukodystrophy and multiple sulfatase deficiency: sulfatase lipidosis. In: Scriver CR, Beaudet AL, Sly WS, Valle D, eds. The metabolic basis of inherited disease. 6th ed. New York: McGraw-Hill, 1989; $1721-50$.

2 Gieselmann V, von Figura K. Advances in the molecula genetics of metachromatic leukodystrophy. $\mathcal{F}$ Inher Metab Dis 1990;13:560-71.

3 Kreysing HJ, von Figura K, Gieselmann V. The structure of the arylsulfatase A gene. Eur F Biochem 1990;191: 627-31

4 Stein C, Gieselmann V, Kreysing J, et al. Cloning and expression of human arylsulfatase A. F Biol Chem 1989 ; 264:1252-9.

5 Polten A, Fluharty AL, Fluharty CB, Kappler J, von Figura K, Gieselmann V. Molecular basis of different forms of metachromatic leukodystrophy. N Engl f Med 1991;324: metach

6 Barth ML, Fensom A, Harris A. Prevalence of common mutations in the arylsulphatase $\mathrm{A}$ gene in metachromatic eukodystrophy patients diagnosed in Britain. Hum Genet 1993;91:73-7.

7 Herz B, Bach G. Arylsulfatase A in pseudodeficiency. Hum Genet 1984;66:147-50

8 Hohenshutz C, Eich P, Friedl W, Waheed A, Conzelman E, Propping P. Pseudodeficiency of arylsulphatase A: common genetic polymorphism with possible disease implications. Hum Genet 1989;82:45-8.

9 Nelson PV, Carey WF, Morris CP. Population frequency of the arylsulphatase A pseudodeficiency allele. Hum Gene $1991 ; 87: 87-8$.

10 Gieselmann V, Polten A, Kreysing J, von Figura K. Arylsulfatase A pseudodeficiency: loss of a polyadenylation signal and N-glycosylation site. Proc Natl Acad Sci USA 1989;86:9436-40.

11 Gieselmann V. An assay for the rapid detection of the arylsulfatase A pseudodeficiency allele facilitates diagnosis arylsulfatase A pseudodeficiency allele facilitates diagnosis and genetic counselling for metach

12 Shen N, Li Z, Waye JS, Francis G, Chang PL. Complication in the genotypic molecular diagnosis of pseudo arylsulfatase A deficiency. Am $\mathcal{F}$ Med Genet 1993;45:631-7.

13 Lench N, Stainer P, Williamson R. Simple non-invasive method to obtain DNA for gene analysis. Lancet 1988; 1356-8

14 Dulaney JT, Moser HW. Sulphatide lipidosis: metachromatic leucodystrophy. In: Stanbury JB, Wyngaarden JB, Frederickson DS, eds. The metabolic basis of inherited disease. 4th ed. New York: McGraw-Hill, 1978:770-809.

15 Lowry OH, Rosebrough NJ, Farr AL, Randall RJ. Protein measurement with the Folin phenol reagent. $\mathcal{F}$ Biol Chem $1951 ; 193: 265-75$

16 Lee-Vaupel M, Conzelmann E. A simple chromogenic assay for arylsulphatase A. Clin Chim Acta 1987;164:171-80.

17 Montandon AJ, Green P, Giannelli F, Bentley DR. Direct detection of point mutations by mismatch analysis: ap plication to haemophilia B. Nucleic Acids Res 1989;17: 3347-57. 